\title{
Large-scale functional brain networks for consciousness
}

\author{
Myoung-Eun $\mathrm{Han}^{1,2}$, Si-Young Park ${ }^{1,2}$, Sae-Ock Oh ${ }^{1,2}$ \\ ${ }^{1}$ Department of Anatomy, School of Medicine, Pusan National University, Yangsan, ${ }^{2}$ Gene \& Cell Therapy Research Center for Vessel-Associated \\ Diseases, Pusan National University, Yangsan, Korea
}

\begin{abstract}
The generation and maintenance of consciousness are fundamental but difficult subjects in the fields of psychology, philosophy, neuroscience, and medicine. However, recent developments in neuro-imaging techniques coupled with network analysis have greatly advanced our understanding of consciousness. The present review focuses on large-scale functional brain networks based on neuro-imaging data to explain the awareness (contents) and wakefulness of consciousness. Despite limitations, neuroimaging data suggests brain maps for important psychological and cognitive processes such as attention, language, self-referential, emotion, motivation, social behavior, and wakefulness. We considered a review of these advancements would provide new insights into research on the neural correlates of consciousness.
\end{abstract}

Key words: Brain, Network, Consciousness, Awareness, Wakefulness

Received November 24, 2020; Revised January 14, 2021; Accepted January 28, 2021

\section{Introduction}

The definition of consciousness has evolved differently in the philosophy, psychology, and medicine fields [1]. Locke [2] defined consciousness as "the perception of what passes in a man's own mind" in a modern conceptual style. Philosophers apply the term to four main topics (Routledge Encyclopedia of Philosophy, 1998): knowledge in general, intentionality, introspection and phenomenal experience. Perceptual experiences, such as tasting and seeing; bodily-sensational experiences, such as pains, tickles, and itches; imaginative experiences, like those of one's own actions or perceptions; and streams of thought, as in the experience of thinking 'in words' or 'in images' are typical examples of phenomenal consciousness. According to the classical psychoanalytic the-

\section{Corresponding author:}

Sae-Ock Oh (iD

Department of Anatomy, School of Medicine, Pusan National University, Yangsan 50612, Korea

E-mail: hedgehog@pusan.ac.kr ory of Sigmund Freud (APA Dictionary of Psychology, 2020), the region of the psyche contains thoughts, feelings, perceptions, and other aspects of mental life present in awareness. In medicine, the approach to consciousness is pragmatic and involves the treatment of individuals whose brain functions have been damaged by diseases, accidents, or drugs, and the determination of level consciousness by neurological examination $[3,4]$. In this review, we define consciousness simply as "an organism's awareness of something either internal or external to itself" and explore the softer question what brain areas and processes are associated with the emergence and maintenance of consciousness.

Consciousness has two-dimensions: awareness and wakefulness [4-6]. Awareness of consciousness refers to contents of consciousness such as sensory perception, self-reference, emotion, motivation, and social and goal-directed behaviors. Contents of the awareness can be further divided into two components: external vs internal awareness. External awareness involves perceptions formed from sensory information gleaned from the external world (i.e., what we see, hear, smell, and taste) and information derived from visual, auditory, somatosensory-motor, and attention networks. On the

\section{Copyright () 2021. Anatomy \& Cell Biology}

This is an Open Access article distributed under the terms of the Creative Commons Attribution Non-Commercial License (http://creativecommons.org/licenses/by-nc/4.0/) which permits unrestricted non-commercial use, distribution, and reproduction in any medium, provided the original work is properly cited. 
other hand, internal awareness involves stimulus-independent processes such as self-referential, emotional, motivational, social, and goal-directed behaviors. The default mode network (DMN) is mainly related to internal awareness.

Wakefulness is the state of vigilance or alertness. The separation of these dimensions is apparent in unresponsive wakefulness state (UWS) patients [7] and spatial neglect syndrome patients [8]. UWS patients show some signs of wakefulness but no sign of awareness-other than by neuroimaging, and spatial neglect syndrome patients show no conscious awareness of visual stimuli though they are awake. Although these two dimensions are different, neural processes associated with both have been shown to interact. The interaction between wakefulness processes, which are regulated by vertical connectivity (brain stem-thalamus-cortex), and awareness processes, which are regulated by horizontal connectivity (cortico-cortical communication), is introduced briefly at the end of this review.

Three components are required for conscious processes: structural connectivity, functional connectivity, and dynamic communications between these components [9]. Structural connectivity means physical connectivity, which can be revealed by neuroanatomical methods such as neural tracing and neuro-imaging methods like diffusion tensor imaging. Functional connectivity means a transient organization of clusters for the computation of specific psychological or cognitive processes. Although brain regions are anatomically connected (the connectome), all regions cannot be connected simultaneously for specific psychological or cognitive processes. Nonetheless, specific functional brain networks play critical roles in conscious processes. In this review, we mainly focus on functional connectivity.

Although neuroanatomical and neurophysiological approaches have added much to our understanding of the awareness of consciousness, recent progress in this field has been made mainly using neuroimaging techniques such as functional magnetic resonance imaging (fMRI) and PET. Together with graph theory-based analysis of neuro-imaging data, these techniques enable the brain mapping of many psychological and cognitive processes. Blood oxygen level dependent (BOLD) scans can be acquired by fMRI, and by using BOLD signals, the co-activation pattern of regions of interest (ROI) (path lengths and clustering coefficients) are calculated by graph theory analysis. The reservoir of fMRI data has been expanded; more than 3,800 functional neuroimaging papers were published in 2020 alone. Interestingly,

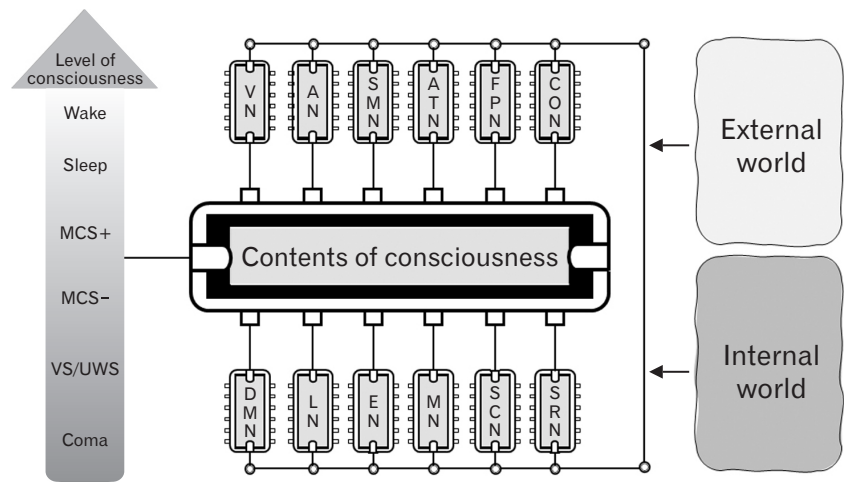

Fig. 1. The Structure of Consciousness. We are aware of external and internal worlds due to the activities of various large-scale functional brain networks. In addition, level of consciousness can affect the contents of consciousness. VN, visual network; AN, auditory network; SMN, somatosensory-motor network; ATN, attention network; FPN, frontoparietal network; CON, cingulo-opercular network; DMN, default mode network; LN, language network; EN, emotional network; MN, motivation network; SCN, social cognition network; SRN, self-referential network; Wake, wakefulness; MCS, minimally conscious state; VS, vegetative state; UWS, unresponsive wakefulness syndrome.

a new software package called NeuroSynth (https://neurosynth.org/, Supplementary Information) has been developed for the large-scale collation and synthesis of human neuroimaging data [10]. This technique combines text-mining, meta-analysis, and machine-learning techniques to generate probabilistic mappings between cognitive and neural states. In this review, we mainly focus on progress made using neuro-imaging techniques but also address progress in the neuroanatomical and neurophysiological fields. In addition, we present the results of meta-analysis using the NeuroSynth web tool (Figs. 1 and 2).

Initially, we review major large-scale functional brain networks associated with the horizontal connectivity (cortico-cortical communication) that underlies awareness of consciousness (attention/language/default mode networks). However, primary sensory and motor networks, including visual, auditory, and somatosensory-motor networks, are not reviewed. This is followed by a review of the wakefulness network that is associated with vertical connectivity (subcortical-cortical communication). Finally, we introduce the interaction between horizontal and vertical connectivity.

\section{Attention Network}

The attention system can be classified into orienting and executive networks [11]. The orienting attention network 

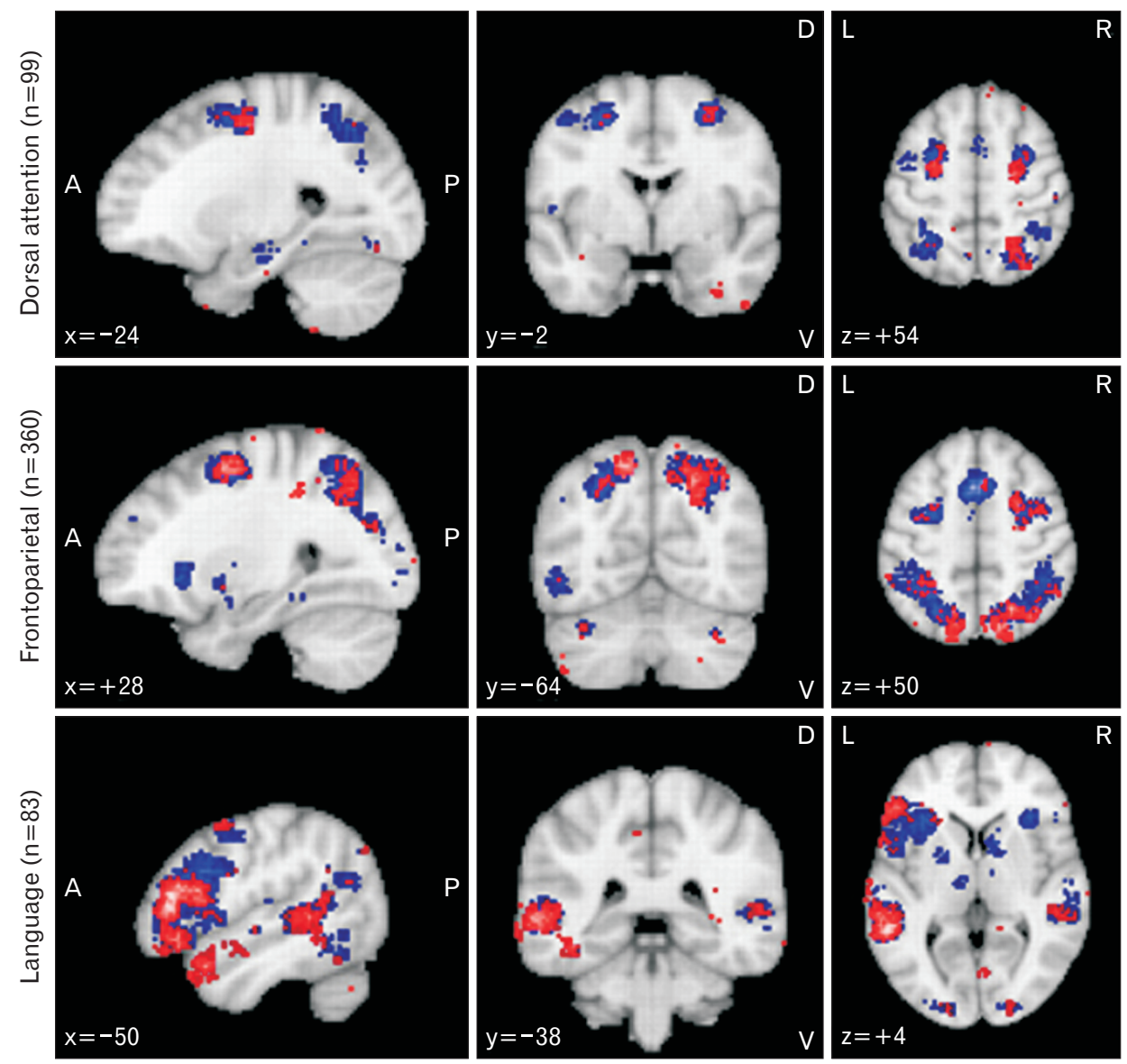

Fig. 2. Attention and language network. Results of meta-analyses on attention and language network obtained from neurosynth.org. The search terms used were "Dorsal Attention" ( $\mathrm{n}=99$ studies); "Frontoparietal Network" ( $\mathrm{n}=$ 360 studies); and "Language Network" ( $\mathrm{n}=83$ studies). Association test and uniformity test map results are shown in red and blue; respectively. Only positive results are depicted. Results are false discovery rate (FDR) corrected at $P<0.01$. Further details are available at neurosynth.org.

is involved in the orientation of external (vision or other) stimuli. This network can prioritize inputs by selecting a modality or location. The brain areas involved are divided into dorsal and ventral attention networks (VAN). The dorsal attention network (DAN) is associated with top-down visuospatial orientation $[12,13]$ and enables the orientation to external stimuli and directs motor or eye movements [14]. The brain areas involved (Fig. 1) include the frontal eye field (FEF) and the superior parietal lobe (SPL)/intraparietal sulcus (IPS) [15]. The VAN is associated with switch and bottom-up reorientation, and the involved brain areas include the ventral frontal cortex (middle and inferior frontal gyrus [IFG]) and the temporoparietal junction (TPJ) [16]. Interestingly, synchronization between the orienting network and primary sensory brain areas, such as the visual area, enhance the sensory sensitivity [17].

The executive network handles target selection and focal attention [18-21]. In task experiments, this network showed greater activity for targets than nontargets, for conflict than for non-conflict trials, and for incorrect rather than cor- rect trials. This network is also associated with top-down regulation, self-control, problem-solving, planning, and goal implementation. The executive network can be divided into the frontoparietal and cingulo-opercular networks. Task experiments have shown that the frontoparietal network controls task switching after a start-cue and the initiation of adjustments within trials. This network mainly involves lateral frontal and parietal regions (Fig. 1). On the other hand, the cingulo-opercular network controls the background maintenance of task performance across trials and performancemonitoring. The medial frontal/cingulate cortex and anterior insula (AI) are involved in the cingulo-opercular network, and interestingly Von Economo neurons, which are found in higher mammals, are located in this network [22].

\section{Language Network}

Visual stimuli such as words and sentences can evoke a language network (LAN), and the existence of this network is suggested by several neurological symptoms such as senso- 

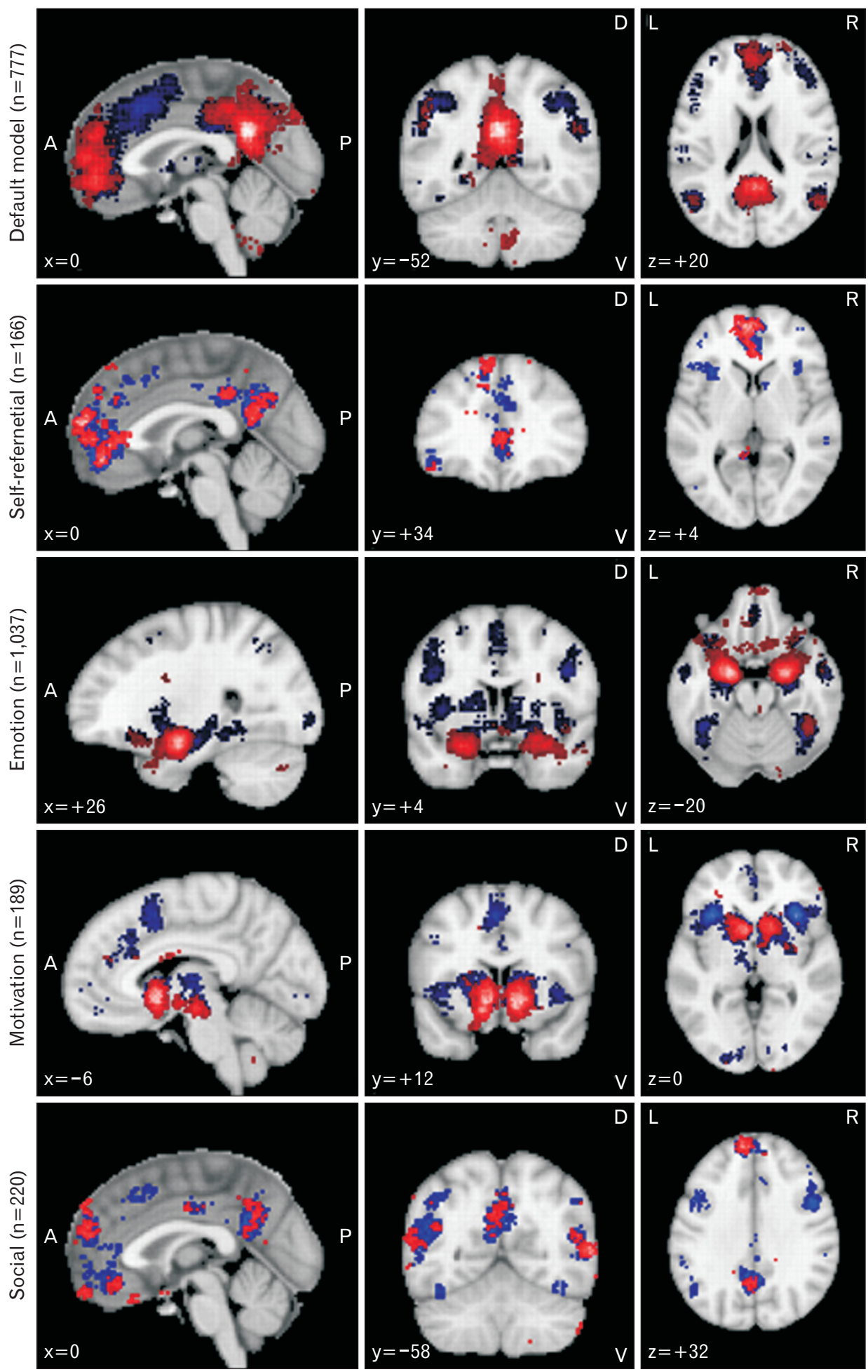

Fig. 3. Default mode network. Results of meta-analysis for the default mode network obtained from neurosynth.org. The search terms used were "Default Mode" (n=777 studies); "Self-referential" ( $\mathrm{n}=166$ studies); "Emotion" ( $\mathrm{n}=1,037$ studies); "Motivation" ( $\mathrm{n}=189$ studies) and "Social Cognition" ( $\mathrm{n}=220$ studies). Association test and uniformity test map results are shown in red and blue; respectively. Only positive results are shown. Results are false discovery rate (FDR) corrected at $P<0.01$. Further details are available at neurosynth.org.

ry, motor and conduction aphasia and by the results of fMRI studies [23-26]. Furthermore, left lateralization of the LAN has been reported $[27,28]$. Its main components include many regions located in frontal, parietal, and temporal lobes
(Fig. 1). Connection pathways between its components can be classified into two groups [29-31]. The ventral pathway is mainly involved in processing visual information into meaning (semantics), and the other, the dorsal pathway is mainly 
associated with visuo-phonology.

The inferior fronto-occipital fasciculus (IFOF), inferior longitudinal fasciculus (ILF) and uncinated fasciculus (UF) constitute the ventral sematic pathway, in which the IFOF connects the occipital cortex, superior parietal lobule, and fusiform gyrus with the IFG and dorsolateral prefrontal cortex (DLPFC). The ventral sematic pathway is critical for verbal and nonverbal semantic procession, and electrical stimulation of this pathway has been reported to cause semantic paraphasia $[29,32,33]$. The ILF links the occipital cortex with the anterior temporal lobe and provides critical pluri-modal integration of multiple semantic-related signals [34]. The UF, which plays a role in proper name retrieval [35], connects the temporal pole (TP) with the pars orbitalis of the IFG $[36,37]$.

The arcuate fasciculus (AF) constitutes the dorsal pathway. Its deep component connects posterior parts of the middle temporal gyrus (MTG) and inferior temporal gyrus (ITG) with the IFG, pars triangularis, and opercularis [38]. The AF is involved in phonological processing and its lesions can induce conduction aphasia $[39,40]$. The superficial component (superior longitudinal fasciculus [SLF] III or the horizontal component of the AF) connects the supramarginal gyrus (SMG) and posterior part of the superior temporal gyrus (STG) with the ventral premotor cortex and contributes to the translation of phonological data into articulatory motor programs $[38,41]$.

\section{Default Mode Network}

The existence of the DMN was suggested by Shulman et al. (1997) [42]. This network subserves internal mentation including self-reference, emotion, and motivation (Fig. 3). The DMN can be deactivated by focusing on the external world [43-45]. Although the topic remains under debate, some core cortical areas of the DMN usually include the ventral medial prefrontal cortex (VMPFC), the dorsal medial prefrontal cortex (DMPFC), the posterior cingulate/retrosplenial cortex (PCC/Rsp), the inferior parietal lobule (IPL), the lateral temporal cortex (LTC), and the hippocampal formation (HF) (Fig. 2). Also, most researchers agree there are from one to nine subnetworks $[46,47]$. In a recent study that used the within-individual approach instead of the groupaverage approach, it was suggested that the DMN consists of nine subnetworks, which include the parietal, ventromedial, pregenual, retrosplenial, posterior medial temporal lobe, and four lateral networks [47]. Interestingly, these four lateral networks work as connecting hubs that link to other large-scale networks such as the language and frontoparietal networks. The parietal network functions as a central coordinator among these nine subnetworks and is related to internal mentation and social cognition $[45,48]$ and includes brain areas such as the medial parietal cortex, middle angular gyrus, anterior VMPFC, anterior medial superior frontal gyrus, middle lateral superior frontal gyrus, anterior superior temporal sulcus, ventral posterior cerebellar lobe, and vermis. The ventromedial subnetwork has been associated with fear and anxiety $[49,50]$ and contains brain areas such as the VMPFC, amygdala, and anterior hippocampus. The pregenual subnetwork has been associated with reward, expected value, decision-related positive emotion, and salience [50-55] and contains brain areas such as the pregenual MPFC, anterior striatum, and ventral AI. The retrosplenial subnetwork has been reported to be involved in the processing of contextual and scene information [56] and contains the Rsp, parieto-occipital fissure, and parahippocampal cortex. The posterior medial temporal lobe subnetwork is critical for long-term memory [57-61] and includes the posterior medial temporal cortex and caudal hippocampus.

\section{Self-referential network}

The self-referential network is one of the most critical networks in DMN because thoughts about self predominate during the resting state. In contrast with other referential processes, self-referential processes can be defined from various perspectives and handled by several kinds of self such as executive self, observing self, neutral self, emotional self, and others [62]. Executive self is associated with the frontoparietal and DAN, whereas emotional self is related to the affective network. Observing self means observing self as an object. Unlike emotional self, neutral self is unaffected by emotion and occurs spontaneously in the resting state compared, whereas observing self usually requires active attention to observe self.

The MPFC is the most critical brain area of the selfreferential network and can be divided into four areas (V-, M-, D1-, D2-PFC) [62-64]. V- (Area 11) and D2- (Area 8) are associated with emotional and executive processes, respectively $[65,66]$, and M- (Area 10) and D1-(Area 9) are associated with neutral and observing selfs, respectively $[67,68]$. For self-referential processes, other areas such as the anterior cingulate cortex (ACC), PCC, precuneus (PrC), insula and 
IPL/TPJ are also involved (Fig. 2). Based on analyses of the effective network, PCC, and PrC areas send signals continuously to the MPFC, which then presents selected signals to consciousness [69-71]. In this model, posterior midline structures are critical for the integration of information from interoception and exteroception.

\section{Emotion and motivation network}

Emotions can be defined as organized affective reactions to significant internal and external events [72, 73]. Extensive studies have been conducted to explain the neurobiological basis of emotions, which range from the Papez circuit to the theory of constructed emotion. Because the emotional network processes various emotions (e.g., fear, anxiety, anger, sadness, and happiness), it may consist of heterogeneous subnetworks. Recently, three new theories encapsulating concepts of emotion were suggested; affective neuroscience theory [73-76], reward sensitivity theory [77], and the theory of constructed emotions [78]. Affective neuroscience theory suggests that basic emotions are evolutionarily conserved in non-human animals. In several studies, ultrasonic vocalizations (USVs) were used to detect the affective statuses of non-human animals [79-81]. Furthermore, efforts have been made to localize seven types of emotion (seeking, lust, care, play, fear, anger/rage, panic/sadness) in the brain map [82]. Although basic emotions are evolutionarily conserved across species, results from non-human animals have yet to be confirmed in man. Reward sensitivity theory describes three systems in brain that link stimuli and responses, i.e., the behavioral activation system (BAS), the fight-flight-freezing system (FFFS), and the behavioral inhibition system (BIS). The BAS and FFFS involve appetitive stimuli and threats, respectively, whereas the BIS promotes exploratory behaviors in unfamiliar situations. The theory of constructed emotion suggests that emotions are constructed by the brain to aid understanding of incoming environmental information.

Brain areas involved in the emotional network usually include the VMPFC, amygdala, ACC, PCC, insula, thalamus, and periaqueductal gray matter [72] (Fig. 2), and activations of these areas depending on emotion type. For example, a proximal threat can activate periaqueductal gray matter and central nuclei of the amygdala [83], but a distant threat activates the VMPFC. A recent study that used multivariate pattern classification showed that distinct subnetworks representing different emotions are observed in the DMN [84].

Motivation can be defined as a process that determines direction and energization [72]. Although motivation is more related to behavior-production and emotion to experiential processes, the motivation network is associated with the emotional network in several respects. Many emotional states promote behaviors that are essential components of motivation [85], for example, anger can provoke offensive behaviors, and in the conditioned place preference test, animals prefer a location associated with reward [86]. Moreover, neuroanatomical areas associated with emotion or motivation tend to overlap. Kim et al. proposed a model to explain motivational behavior $[87,88]$. According to this model, the motivation process consists of three phases: generation (anticipation of reward), maintenance (value-based decision making), and modulation (cognitive regulatory control). The motivation network usually includes the ventral tegmental area, nucleus accumbens (NAcc), ventral striatum (VS), amygdala, and MPFC (Fig. 2), and the NAcc and mesolimbic pathways are critical for the generation of motivation $[89,90]$. The activity of the NAcc is correlated with degree of excitement, and connectivity between the MPFC and VS is critical for grit [72]. Connectivity between the dorsal anterior cingulate cortex (dACC) and dorsal and VS is associated with growth mindset [91], and the orbitofrontal cortex (OFC) is important for value evaluation [87].

\section{Social cognition network}

Like other social animals, humans can 'sense' the mental states of others [92], that is, we can reasonably predict the emotional statuses (empathy), intentions, and perspectives (Theory of Mind) of others, and based on our perceptions, we perform prosocial activities that reward these others. Furthermore, these prosocial activities are critical for eliciting healthy social interactions. Empathy can be defined as the ability to understand and share the affective states of others, and the anterior cingulate gyrus (ACCg) and subgenual anterior cingulate gyrus (sgACC) are usually involved in the process of empathy $[92,93]$. The Theory of Mind concerns ability to assess the mental states of others [94-96], and several kinds of tests such as the Sally-Ann test, the dot perspective task, and the ambiguous figure perception test support this theory $[97,98]$. Perspective-taking mainly involves the TPJ, DMPFC, and PrC (Theory of Mind) [99-101]. Prosocial activity refers to actions undertaken to obtain a reward for another person despite the personal effort/cost involved, and this activity largely involves the sgACC and TPJ [92, 102-104].

Goal-directed behaviors derived from social or non-social 
motivation are based on subjective valuation, which computes physical and cognitive efforts and rewards. Neuronal activities in the dACC, AI, VS, basolateral amygdala (BLA), VMPFC, and DLPFC have been shown by fMRI studies to be correlated with efforts and rewards [105-107]. Moreover, single-cell recordings have shown that a subset of neurons in the dACC signal the amount of reward on offer, and another neuron subset in the same area signals the amount of effort required $[108,109]$.

\section{Wakefulness Network}

Wakefulness refers to levels of arousal and behavioral states during which an animal exhibits voluntary motor activation and is responsive to internal and external stimuli [110]. Wakefulness states can be described as: comatose, vegetative (unresponsive wakefulness syndrome), or minimally conscious [3]. During the comatose state, patients do not respond to extensive stimuli. In the vegetative state patients exhibit spontaneous breathing, spontaneous or stimulusinduced eye opening, blinking to a visual threat, auditory startle response, orient eyes or head to stimuli, stereotyped posturing, and show normal flexion withdrawal to noxious stimuli and gag/deglutination/oral reflex. The minimally conscious state (MCS) can be further divided into two states: MCS+ and MCS-. Patients in the MCS- state show simple non-reflex movements (visual pursuit, orientation to pain or non-contingent behavior [smiling]), and those in the MCS+ state respond to simple commands. These behaviors suggest MCS patients have some degree of cortico-cortical communication but that communication is poor in UWS patients. Level of wakefulness is also naturally regulated by circadian rhythm (sleep cycle) [110]. Polysomnography (EEG, electrooculography, and electromyography) results show natural sleep can be divided into non-rapid eye movement (NREM) sleep (N1, relaxed wakefulness; N2, light sleep; N3, deep sleep), and REM sleep.

Level of wakefulness is regulated by vertical connectivity from the brain stem (reticular formation system, locus ceruleus, ventral tegmental nucleus, raphe nucleus, and others) through hypothalamus and thalamus to cortex [110, 111], and damage to this vertical connectiveness can alter the status of wakefulness [112, 113]. During slow-wave sleep, low frequency synchronized activity between the cortex and thalamus blocks sensory input to the cortex [114]. However, when awake, thalamocortical activity is attenuated. More- over, contents of awareness can alter depending on the level of wakefulness.

The suprachiasmatic nucleus is the central pacemaker of circadian rhythm and regulates wake-promoting, sleep-promoting, and REM-producing circuits in a time-dependent manner $[115,116]$. Orexin-positive neurons in the lateral hypothalamus [117-119], cholinergic neurons in pedunculopontine and laterodorsal tegmental nuclei $[120,121]$, monoaminergic neurons in locus coeruleus [122, 123], dorsal and median raphe nuclei $[124,125]$, and ventral tegmental nuclei $[126,127]$ and histaminergic neurons $[128,129]$ constitute wake-promoting circuits. These circuits might be divided into two pathways, i.e., the ventral and dorsal pathways [110]. The former links brain stem areas with hypothalamus, basal brain, and cortex, and regulates the behavioral state of wakefulness, whereas the dorsal pathway links brain stem areas with thalamus and regulates contents of consciousness. GABAergic neurons in ventrolateral and median preoptic nuclei regulate sleep-promoting circuits [130, 131], and glutamatergic neurons in the sublaterodorsal nucleus $[132,133]$ and cholinergic neurons in the pedunculopontine and laterodorsal tegmental nuclei are important for REM-promoting circuits $[134,135]$.

\section{Interaction between Horizontal and Vertical Connectivity}

The activities of large-scale brain networks have been reported to depend on level of wakefulness. A recent study analyzed the dependence of spatiotemporal dynamics of large-scale brain networks on sleep stages [136] and showed that up to 10 brain networks can co-occur. The average number of co-occurring networks found was 2-5, and the mean duration of each network was 7.3 seconds. Activities of all brain networks are maintained through sleep stages and are maximally activated during the N2 stage. Notably functional interrelations between networks decrease in the deep sleep stage. During this stage, connectivity between the MPFC and PCC in the DMN and activity of the attention network decrease, whereas the activity of the posterior DMN increases. In addition, the duration of brain network activity decreases in the deep sleep stage, which suggests corticocortical connectivity breakdown.

Spatiotemporal dynamics of brain networks have also been examined in drug-induced (ketamine and propofol) states of altered wakefulness and in the presence of neuro- 
pathologies (UWS) [137]. This study showed reduced brain network entropy and uniformity of the occurrence rates of different brain networks in unresponsive states. Interestingly, it was also shown that preferred transition trajectories exist between brain networks. In the conscious state, accessibility to different brain networks is well maintained, but in unresponsive states, visual (VIS) and VAN networks are monopolized, and the negative correlation between DMN and DAN is attenuated. Accordingly, sleep stage studies show the persistence probabilities of brain networks are reduced in unresponsive states.

\section{Future Direction}

In the present study, we reviewed major large-scale functional brain networks related to consciousness. Brain mapping of networks has been largely performed using neuroimaging data. However, because the brain is composed of neurons and glial cells, further studies are needed to explore the cellular-scale mechanisms subserving consciousness to identify its neural correlates. Cellular-scale mechanisms should explain how distant brain regions are connected or coupled transiently to achieve functional connectivity. Because one specific stimulus should not activate all anatomically connected brain regions for specific psychological or cognitive processes, unnecessary coupling needs to be inhibited to establish specific neural networks. Recently microand macro-circuits have been suggested for long-distance connections between brain areas. Glutamate release from distant pyramidal neurons can activate target pyramidal neurons and vasoactive intestinal peptide (VIP)-positive GABAergic interneurons [138-141], and thus, modulate the feedback loop between GABAergic interneurons and pyramidal interneurons. This disynaptic disinhibition generates gamma oscillations in distant pyramidal neurons and stabilizes local information. Moreover, the selective activations of subnetworks and inactivations of other subnetworks can be achieved by inhibiting $\alpha$ oscillation-induced gating [142-145]. More detailed mechanistic studies are needed to characterize the micro- and macro-circuits underlying consciousness.

\section{ORCID}

Myoung-Eun Han:

https://orcid.org/0000-0001-6083-0485

Si-Young Park: https://orcid.org/0000-0003-1193-7264
Sae-Ock Oh: https://orcid.org/0000-0002-9365-7831

\section{Author Contributions}

Conceptualization: MEH, SOO. Data acquisition: SYP. Data analysis or interpretation: SOO. Drafting of the manuscript: $\mathrm{MEH}$. Critical revision of the manuscript: $\mathrm{MEH}$, SOO. Approval of the final version of the manuscript: all authors.

\section{Conflicts of Interest}

No potential conflict of interest relevant to this article was reported.

\section{Acknowledgements}

This work was supported by a 2-year Research Grant of Pusan National University.

\section{References}

1. Harnad S. Explaining consciousness: the hard problem. Trends Cogn Sci 1998;2:234-5.

2. Locke J. An essay concerning human understanding. Amherst: Prometheus Books; 1995. 624 p.

3. Demertzi A, Soddu A, Laureys S. Consciousness supporting networks. Curr Opin Neurobiol 2013;23:239-44.

4. Laureys S. The neural correlate of (un)awareness: lessons from the vegetative state. Trends Cogn Sci 2005;9:556-9.

5. Zhao T, Zhu Y, Tang H, Xie R, Zhu J, Zhang JH. Consciousness: new concepts and neural networks. Front Cell Neurosci 2019;13:302.

6. Bayne T, Hohwy J, Owen AM. Are there levels of consciousness? Trends Cogn Sci 2016;20:405-13.

7. Laureys S, Boly M. Unresponsive wakefulness syndrome. Arch Ital Biol 2012;150:31-5.

8. Le A, Stojanoski BB, Khan S, Keough M, Niemeier M. A toggle switch of visual awareness? Cortex 2015;64:169-78.

9. Modolo J, Hassan M, Wendling F, Benquet P. Decoding the circuitry of consciousness: from local microcircuits to brainscale networks. Netw Neurosci 2020;4:315-37.

10. Yarkoni T, Poldrack RA, Nichols TE, Van Essen DC, Wager TD. Large-scale automated synthesis of human functional neuroimaging data. Nat Methods 2011;8:665-70.

11. Petersen SE, Posner MI. The attention system of the human brain: 20 years after. Annu Rev Neurosci 2012;35:73-89.

12. Corbetta M, Akbudak E, Conturo TE, Snyder AZ, Ollinger JM, Drury HA, Linenweber MR, Petersen SE, Raichle ME, Van Essen DC, Shulman GL. A common network of function- 
al areas for attention and eye movements. Neuron 1998;21:76173.

13. Thompson KG, Biscoe KL, Sato TR. Neuronal basis of covert spatial attention in the frontal eye field. J Neurosci 2005;25:9479-87.

14. Lindner A, Iyer A, Kagan I, Andersen RA. Human posterior parietal cortex plans where to reach and what to avoid. J Neurosci 2010;30:11715-25.

15. Davidson MC, Marrocco RT. Local infusion of scopolamine into intraparietal cortex slows covert orienting in rhesus monkeys. J Neurophysiol 2000;83:1536-49.

16. Corbetta M, Shulman GL. Control of goal-directed and stimulus-driven attention in the brain. Nat Rev Neurosci 2002;3:20115 .

17. Womelsdorf T, Schoffelen JM, Oostenveld R, Singer W, Desimone R, Engel AK, Fries P. Modulation of neuronal interactions through neuronal synchronization. Science 2007;316:1609-12.

18. Dosenbach NU, Visscher KM, Palmer ED, Miezin FM, Wenger KK, Kang HC, Burgund ED, Grimes AL, Schlaggar BL, Petersen SE. A core system for the implementation of task sets. Neuron 2006;50:799-812.

19. Dosenbach NU, Fair DA, Miezin FM, Cohen AL, Wenger KK, Dosenbach RA, Fox MD, Snyder AZ, Vincent JL, Raichle ME, Schlaggar BL, Petersen SE. Distinct brain networks for adaptive and stable task control in humans. Proc Natl Acad Sci U S A 2007;104:11073-8.

20. Dosenbach NU, Fair DA, Cohen AL, Schlaggar BL, Petersen SE. A dual-networks architecture of top-down control. Trends Cogn Sci 2008;12:99-105.

21. Botvinick MM, Braver TS, Barch DM, Carter CS, Cohen JD. Conflict monitoring and cognitive control. Psychol Rev 2001;108:624-52.

22. Allman JM, Watson KK, Tetreault NA, Hakeem AY. Intuition and autism: a possible role for Von Economo neurons. Trends Cogn Sci 2005;9:367-73.

23. Glasser MF, Coalson TS, Robinson EC, Hacker CD, Harwell J, Yacoub E, Ugurbil K, Andersson J, Beckmann CF, Jenkinson M, Smith SM, Van Essen DC. A multi-modal parcellation of human cerebral cortex. Nature 2016;536:171-8.

24. Gazzaniga MS. Forty-five years of split-brain research and still going strong. Nat Rev Neurosci 2005;6:653-9.

25. Cole MW, Reynolds JR, Power JD, Repovs G, Anticevic A, Braver TS. Multi-task connectivity reveals flexible hubs for adaptive task control. Nat Neurosci 2013;16:1348-55.

26. Ji JL, Spronk M, Kulkarni K, Repovš G, Anticevic A, Cole MW. Mapping the human brain's cortical-subcortical functional network organization. Neuroimage 2019;185:35-57.

27. Mesulam MM. From sensation to cognition. Brain 1998;121 ( Pt 6):1013-52.

28. McAvoy M, Mitra A, Coalson RS, d'Avossa G, Keidel JL, Petersen SE, Raichle ME. Unmasking language lateralization in human brain intrinsic activity. Cereb Cortex 2016;26:1733-46.

29. Herbet G, Duffau $H$. Revisiting the functional anatomy of the human brain: toward a meta-networking theory of cerebral functions. Physiol Rev 2020;100:1181-228.

30. Duffau H, Moritz-Gasser S, Mandonnet E. A re-examination of neural basis of language processing: proposal of a dynamic hodotopical model from data provided by brain stimulation mapping during picture naming. Brain Lang 2014;131:1-10.

31. Hickok G, Poeppel D. The cortical organization of speech processing. Nat Rev Neurosci 2007;8:393-402.

32. Herbet G, Moritz-Gasser S, Duffau H. Direct evidence for the contributive role of the right inferior fronto-occipital fasciculus in non-verbal semantic cognition. Brain Struct Funct 2017;222:1597-610.

33. Herbet G, Moritz-Gasser S, Duffau H. Electrical stimulation of the dorsolateral prefrontal cortex impairs semantic cognition. Neurology 2018;90:e1077-84

34. Holland R, Lambon Ralph MA. The anterior temporal lobe semantic hub is a part of the language neural network: selective disruption of irregular past tense verbs by rTMS. Cereb Cortex 2010;20:2771-5.

35. Papagno C, Miracapillo C, Casarotti A, Romero Lauro LJ, Castellano A, Falini A, Casaceli G, Fava E, Bello L. What is the role of the uncinate fasciculus? Surgical removal and proper name retrieval. Brain 2011;134(Pt 2):405-14.

36. Duffau H, Capelle L, Sichez N, Denvil D, Lopes M, Sichez JP, Bitar A, Fohanno D. Intraoperative mapping of the subcortical language pathways using direct stimulations. An anatomofunctional study. Brain 2002;125(Pt 1):199-214.

37. Hau J, Sarubbo S, Houde JC, Corsini F, Girard G, Deledalle C, Crivello F, Zago L, Mellet E, Jobard G, Joliot M, Mazoyer B, Tzourio-Mazoyer N, Descoteaux M, Petit L. Revisiting the human uncinate fasciculus, its subcomponents and asymmetries with stem-based tractography and microdissection validation. Brain Struct Funct 2017;222:1645-62.

38. Martino J, De Witt Hamer PC, Berger MS, Lawton MT, Arnold CM, de Lucas EM, Duffau H. Analysis of the subcomponents and cortical terminations of the perisylvian superior longitudinal fasciculus: a fiber dissection and DTI tractography study. Brain Struct Funct 2013;218:105-21.

39. Maldonado IL, Moritz-Gasser S, Duffau H. Does the left superior longitudinal fascicle subserve language semantics? A brain electrostimulation study. Brain Struct Funct 2011;216:263-74.

40. Dick AS, Tremblay P. Beyond the arcuate fasciculus: consensus and controversy in the connectional anatomy of language. Brain 2012;135(Pt 12):3529-50.

41. van Geemen K, Herbet G, Moritz-Gasser S, Duffau H. Limited plastic potential of the left ventral premotor cortex in speech articulation: evidence from intraoperative awake mapping in glioma patients. Hum Brain Mapp 2014;35:1587-96.

42. Shulman GL, Fiez JA, Corbetta M, Buckner RL, Miezin FM, Raichle ME, Petersen SE. Common blood flow changes across visual tasks: II. Decreases in cerebral cortex. J Cogn Neurosci 1997;9:648-63.

43. Raichle ME. The brain's default mode network. Annu Rev Neurosci 2015;38:433-47.

44. Buckner RL, DiNicola LM. The brain's default network: up- 
dated anatomy, physiology and evolving insights. Nat Rev Neurosci 2019;20:593-608.

45. Buckner RL, Andrews-Hanna JR, Schacter DL. The brain's default network: anatomy, function, and relevance to disease. Ann N Y Acad Sci 2008;1124:1-38.

46. Andrews-Hanna JR, Reidler JS, Sepulcre J, Poulin R, Buckner RL. Functional-anatomic fractionation of the brain's default network. Neuron 2010;65:550-62.

47. Gordon EM, Laumann TO, Marek S, Raut RV, Gratton C, Newbold DJ, Greene DJ, Coalson RS, Snyder AZ, Schlaggar BL, Petersen SE, Dosenbach NUF, Nelson SM. Default-mode network streams for coupling to language and control systems. Proc Natl Acad Sci U S A 2020;117:17308-19.

48. DiNicola LM, Braga RM, Buckner RL. Parallel distributed networks dissociate episodic and social functions within the individual. J Neurophysiol 2020;123:1144-79.

49. Kalisch R, Korenfeld E, Stephan KE, Weiskopf N, Seymour B, Dolan RJ. Context-dependent human extinction memory is mediated by a ventromedial prefrontal and hippocampal network. J Neurosci 2006;26:9503-11.

50. Hiser J, Koenigs $M$. The multifaceted role of the ventromedial prefrontal cortex in emotion, decision making, social cognition, and psychopathology. Biol Psychiatry 2018;83:638-47.

51. Grabenhorst F, Rolls ET. Value, pleasure and choice in the ventral prefrontal cortex. Trends Cogn Sci 2011;15:56-67.

52. Clithero JA, Rangel A. Informatic parcellation of the network involved in the computation of subjective value. Soc Cogn Affect Neurosci 2014;9:1289-302.

53. Shenhav A, Buckner RL. Neural correlates of dueling affective reactions to win-win choices. Proc Natl Acad Sci U S A 2014;111:10978-83.

54. Shenhav A, Karmarkar UR. Dissociable components of the reward circuit are involved in appraisal versus choice. Sci Rep 2019;9:1958.

55. Smith DV, Hayden BY, Truong TK, Song AW, Platt ML, Huettel SA. Distinct value signals in anterior and posterior ventromedial prefrontal cortex. J Neurosci 2010;30:2490-5.

56. Bar M, Aminoff E. Cortical analysis of visual context. Neuron 2003;38:347-58.

57. Ranganath C, Ritchey M. Two cortical systems for memoryguided behaviour. Nat Rev Neurosci 2012;13:713-26.

58. Squire LR, Stark CE, Clark RE. The medial temporal lobe. Annu Rev Neurosci 2004;27:279-306.

59. Wig GS, Grafton ST, Demos KE, Wolford GL, Petersen SE, Kelley WM. Medial temporal lobe BOLD activity at rest predicts individual differences in memory ability in healthy young adults. Proc Natl Acad Sci U S A 2008;105:18555-60.

60. Lee JH, Cheon YH, Woo RS, Song DY, Moon C, Baik TK. Evidence of early involvement of apoptosis inducing factorinduced neuronal death in Alzheimer brain. Anat Cell Biol 2012;45:26-37.

61. Kim YH, Park JH. Vanillin and 4-hydroxybenzyl alcohol attenuate cognitive impairment and the reduction of cell proliferation and neuroblast differentiation in the dentate gyrus in a mouse model of scopolamine-induced amnesia. Anat Cell Biol 2017;50:143-51.

62. Frewen P, Schroeter ML, Riva G, Cipresso P, Fairfield B, Padulo C, Kemp AH, Palaniyappan L, Owolabi M, Kusi-Mensah K, Polyakova M, Fehertoi N, D'Andrea W, Lowe L, Northoff G. Neuroimaging the consciousness of self: review, and conceptual-methodological framework. Neurosci Biobehav Rev 2020;112:164-212.

63. Kober H, Barrett LF, Joseph J, Bliss-Moreau E, Lindquist K, Wager TD. Functional grouping and cortical-subcortical interactions in emotion: a meta-analysis of neuroimaging studies. Neuroimage 2008;42:998-1031.

64. Legrand D, Ruby P. What is self-specific? Theoretical investigation and critical review of neuroimaging results. Psychol Rev 2009;116:252-82.

65. Buhle JT, Silvers JA, Wager TD, Lopez R, Onyemekwu C, Kober H, Weber J, Ochsner KN. Cognitive reappraisal of emotion: a meta-analysis of human neuroimaging studies. Cereb Cortex 2014;24:2981-90.

66. Koush Y, Pichon S, Eickhoff SB, Van De Ville D, Vuilleumier $\mathrm{P}$, Scharnowski F. Brain networks for engaging oneself in positive-social emotion regulation. Neuroimage 2019;189:10615.

67. Dörfel D, Lamke JP, Hummel F, Wagner U, Erk S, Walter H. Common and differential neural networks of emotion regulation by Detachment, Reinterpretation, Distraction, and Expressive Suppression: a comparative fMRI investigation. Neuroimage 2014;101:298-309.

68. Kalisch R, Wiech K, Critchley HD, Seymour B, O’Doherty JP, Oakley DA, Allen P, Dolan RJ. Anxiety reduction through detachment: subjective, physiological, and neural effects. J Cogn Neurosci 2005;17:874-83.

69. Davey CG, Pujol J, Harrison BJ. Mapping the self in the brain's default mode network. Neuroimage 2016;132:390-7.

70. Davey CG, Breakspear M, Pujol J, Harrison BJ. A brain model of disturbed self-appraisal in depression. Am J Psychiatry 2017;174:895-903.

71. Ruby P, Decety J. How would you feel versus how do you think she would feel? A neuroimaging study of perspective-taking with social emotions. J Cogn Neurosci 2004;16:988-99.

72. Cromwell HC, Abe N, Barrett KC, Caldwell-Harris C, Gendolla GHE, Koncz R, Sachdev PS. Mapping the interconnected neural systems underlying motivation and emotion: a key step toward understanding the human affectome. Neurosci Biobehav Rev 2020;113:204-26.

73. Markett S, Wudarczyk OA, Biswal BB, Jawinski P, Montag C. Affective network neuroscience. Front Neurosci 2018;12:895.

74. Panksepp J. Affective neuroscience of the emotional BrainMind: evolutionary perspectives and implications for understanding depression. Dialogues Clin Neurosci 2010;12:533-45.

75. Montag C, Widenhorn-Müller K, Panksepp J, Kiefer M. Individual differences in Affective Neuroscience Personality Scale (ANPS) primary emotional traits and depressive tendencies. Compr Psychiatry 2017;73:136-42. 
76. Davis KL, Montag C. A Tribute to Jaak Panksepp (1943-2017). Personal Neurosci 2018;1:e9.

77. Gilson M, Deco G, Friston KJ, Hagmann P, Mantini D, Betti V, Romani GL, Corbetta M. Effective connectivity inferred from fMRI transition dynamics during movie viewing points to a balanced reconfiguration of cortical interactions. Neuroimage 2018;180(Pt B):534-46.

78. Barrett LF. The theory of constructed emotion: an active inference account of interoception and categorization. Soc Cogn Affect Neurosci 2017;12:1833.

79. Knutson B, Burgdorf J, Panksepp J. Ultrasonic vocalizations as indices of affective states in rats. Psychol Bull 2002;128:96177.

80. Cromwell HC, Atchley RM. Influence of emotional states on inhibitory gating: animals models to clinical neurophysiology. Behav Brain Res 2015;276:67-75.

81. Wöhr M, Seffer D, Schwarting RK. Studying socio-affective communication in rats through playback of ultrasonic vocalizations. Curr Protoc Neurosci 2016;75:8.35.1-8.35.17.

82. Panksepp J. Cross-species affective neuroscience decoding of the primal affective experiences of humans and related animals. PLoS One 2011;6:e21236.

83. Mobbs D, Petrovic P, Marchant JL, Hassabis D, Weiskopf N, Seymour B, Dolan RJ, Frith CD. When fear is near: threat imminence elicits prefrontal-periaqueductal gray shifts in humans. Science 2007;317:1079-83.

84. Saarimäki H, Glerean E, Smirnov D, Mynttinen H, Jääskeläinen IP, Sams M, Nummenmaa L. Classification of emotions based on functional connectivity patterns of the human brain. BioRxiv 910869 [Preprint]. 2020 [cited 2020 Jan 18]. Available from: https://doi.org/10.1101/2020.01.17.910869

85. Tomkins SS. Script theory: differential magnification of affects. Nebr Symp Motiv 1978;26:201-36.

86. Lahvis GP, Panksepp JB, Kennedy BC, Wilson CR, Merriman DK. Social conditioned place preference in the captive ground squirrel (Ictidomys tridecemlineatus): social reward as a natural phenotype. J Comp Psychol 2015;129:291-303.

87. Kim SI. Neuroscientific model of motivational process. Front Psychol 2013;4:98.

88. Haber SN, Knutson B. The reward circuit: linking primate anatomy and human imaging. Neuropsychopharmacology 2010;35:4-26

89. Bjork JM, Knutson B, Fong GW, Caggiano DM, Bennett SM, Hommer DW. Incentive-elicited brain activation in adolescents: similarities and differences from young adults. J Neurosci 2004;24:1793-802.

90. Peterson RL. The neuroscience of investing: fMRI of the reward system. Brain Res Bull 2005;67:391-7.

91. Myers CA, Wang C, Black JM, Bugescu N, Hoeft F. The matter of motivation: striatal resting-state connectivity is dissociable between grit and growth mindset. Soc Cogn Affect Neurosci 2016;11:1521-7.

92. Contreras-Huerta LS, Pisauro MA, Apps MAJ. Effort shapes social cognition and behaviour: a neuro-cognitive framework.
Neurosci Biobehav Rev 2020;118:426-39.

93. Lockwood PL, Apps MA, Valton V, Viding E, Roiser JP. Neurocomputational mechanisms of prosocial learning and links to empathy. Proc Natl Acad Sci U S A 2016;113:9763-8.

94. Wimmer H, Perner J. Beliefs about beliefs: representation and constraining function of wrong beliefs in young children's understanding of deception. Cognition 1983;13:103-28.

95. Kovács ÁM, Téglás E, Endress AD. The social sense: susceptibility to others' beliefs in human infants and adults. Science 2010;330:1830-4

96. Meyer ML, Spunt RP, Berkman ET, Taylor SE, Lieberman MD. Evidence for social working memory from a parametric functional MRI study. Proc Natl Acad Sci U S A 2012;109:1883-8.

97. Mahy CE, Moses LJ, Pfeifer JH. How and where: theory-ofmind in the brain. Dev Cogn Neurosci 2014;9:68-81.

98. Cole GG, Millett AC. The closing of the theory of mind: a critique of perspective-taking. Psychon Bull Rev 2019;26:1787802

99. Amodio DM, Frith CD. Meeting of minds: the medial frontal cortex and social cognition. Nat Rev Neurosci 2006;7:268-77.

100. Döhnel K, Schuwerk T, Meinhardt J, Sodian B, Hajak G, Sommer M. Functional activity of the right temporo-parietal junction and of the medial prefrontal cortex associated with true and false belief reasoning. Neuroimage 2012;60:1652-61.

101. Frith U, Frith $\mathrm{C}$. The social brain: allowing humans to boldly go where no other species has been. Philos Trans R Soc Lond B Biol Sci 2010;365:165-76.

102. Bortolini T, Bado P, Hoefle S, Engel A, Zahn R, de Oliveira Souza R, Dreher JC, Moll J. Neural bases of ingroup altruistic motivation in soccer fans. Sci Rep 2017;7:16122.

103. Le Bouc R, Pessiglione M. Imaging social motivation: distinct brain mechanisms drive effort production during collaboration versus competition. J Neurosci 2013;33:15894-902.

104. Wittmann MK, Lockwood PL, Rushworth MFS. Neural mechanisms of social cognition in primates. Annu Rev Neurosci 2018;41:99-118.

105. Bonnelle V, Manohar S, Behrens T, Husain M. Individual differences in premotor brain systems underlie behavioral apathy. Cereb Cortex 2016;26:807-19.

106. Chong TT, Apps M, Giehl K, Sillence A, Grima LL, Husain M. Neurocomputational mechanisms underlying subjective valuation of effort costs. PLoS Biol 2017;15:e1002598.

107. Klein-Flügge MC, Kennerley SW, Friston K, Bestmann S. Neural signatures of value comparison in human cingulate cortex during decisions requiring an effort-reward trade-off. J Neurosci 2016;36:10002-15.

108. Kennerley SW, Wallis JD. Evaluating choices by single neurons in the frontal lobe: outcome value encoded across multiple decision variables. Eur J Neurosci 2009;29:2061-73.

109. Walton ME, Kennerley SW, Bannerman DM, Phillips PE, Rushworth MF. Weighing up the benefits of work: behavioral and neural analyses of effort-related decision making. Neural Netw 2006;19:1302-14.

110. Scammell TE, Arrigoni E, Lipton JO. Neural circuitry of 
wakefulness and sleep. Neuron 2017;93:747-65.

111. Parvizi J, Damasio A. Consciousness and the brainstem. Cognition 2001;79:135-60.

112. Bassetti C, Mathis J, Gugger M, Lovblad KO, Hess CW. Hypersomnia following paramedian thalamic stroke: a report of 12 patients. Ann Neurol 1996;39:471-80.

113. Ranson SW. Some functions of the hypothalamus: Harvey Lecture, December 17, 1936. Bull N Y Acad Med 1937;13:24171.

114. McCormick DA, McGinley MJ, Salkoff DB. Brain state dependent activity in the cortex and thalamus. Curr Opin Neurobiol 2015;31:133-40.

115. Bedont JL, Blackshaw S. Constructing the suprachiasmatic nucleus: a watchmaker's perspective on the central clockworks. Front Syst Neurosci 2015;9:74.

116. Welsh DK, Takahashi JS, Kay SA. Suprachiasmatic nucleus: cell autonomy and network properties. Annu Rev Physiol 2010;72:551-77.

117. de Lecea L, Kilduff TS, Peyron C, Gao X, Foye PE, Danielson PE, Fukuhara C, Battenberg EL, Gautvik VT, Bartlett FS 2nd, Frankel WN, van den Pol AN, Bloom FE, Gautvik KM, Sutcliffe JG. The hypocretins: hypothalamus-specific peptides with neuroexcitatory activity. Proc Natl Acad Sci U S A 1998;95:322-7.

118. Sakurai T, Amemiya A, Ishii M, Matsuzaki I, Chemelli RM, Tanaka H, Williams SC, Richardson JA, Kozlowski GP, Wilson S, Arch JR, Buckingham RE, Haynes AC, Carr SA, Annan RS, McNulty DE, Liu WS, Terrett JA, Elshourbagy NA, Bergsma DJ, Yanagisawa M. Orexins and orexin receptors: a family of hypothalamic neuropeptides and G protein-coupled receptors that regulate feeding behavior. Cell 1998;92:573-85.

119. Branch AF, Navidi W, Tabuchi S, Terao A, Yamanaka A, Scammell TE, Diniz Behn C. Progressive loss of the orexin neurons reveals dual effects on wakefulness. Sleep 2016;39:36977.

120. Wang HL, Morales M. Pedunculopontine and laterodorsal tegmental nuclei contain distinct populations of cholinergic, glutamatergic and GABAergic neurons in the rat. Eur J Neurosci 2009;29:340-58.

121. Cox J, Pinto L, Dan Y. Calcium imaging of sleep-wake related neuronal activity in the dorsal pons. Nat Commun 2016;7:10763.

122. Carter ME, Yizhar O, Chikahisa S, Nguyen H, Adamantidis A, Nishino S, Deisseroth K, de Lecea L. Tuning arousal with optogenetic modulation of locus coeruleus neurons. Nat Neurosci 2010;13:1526-33.

123. Gompf HS, Mathai C, Fuller PM, Wood DA, Pedersen NP, Saper CB, Lu J. Locus ceruleus and anterior cingulate cortex sustain wakefulness in a novel environment. J Neurosci 2010;30:14543-51.

124. Weissbourd B, Ren J, DeLoach KE, Guenthner CJ, Miyamichi K, Luo L. Presynaptic partners of dorsal raphe serotonergic and GABAergic neurons. Neuron 2014;83:645-62.

125. Ito H, Yanase M, Yamashita A, Kitabatake C, Hamada A, Su- hara Y, Narita M, Ikegami D, Sakai H, Yamazaki M, Narita M. Analysis of sleep disorders under pain using an optogenetic tool: possible involvement of the activation of dorsal raphe nucleus-serotonergic neurons. Mol Brain 2013;6:59.

126. Wisor JP, Nishino S, Sora I, Uhl GH, Mignot E, Edgar DM. Dopaminergic role in stimulant-induced wakefulness. J Neurosci 2001;21:1787-94.

127. Eban-Rothschild A, Rothschild G, Giardino WJ, Jones JR, de Lecea L. VTA dopaminergic neurons regulate ethologically relevant sleep-wake behaviors. Nat Neurosci 2016;19:1356-66.

128. Parmentier R, Zhao Y, Perier M, Akaoka H, Lintunen M, Hou Y, Panula P, Watanabe T, Franco P, Lin JS. Role of histamine H1-receptor on behavioral states and wake maintenance during deficiency of a brain activating system: a study using a knockout mouse model. Neuropharmacology 2016;106:20-34.

129. Yu X, Zecharia A, Zhang Z, Yang Q, Yustos R, Jager P, Vyssotski AL, Maywood ES, Chesham JE, Ma Y, Brickley SG, Hastings MH, Franks NP, Wisden W. Circadian factor BMAL1 in histaminergic neurons regulates sleep architecture. Curr Biol 2014;24:2838-44.

130. Saito YC, Tsujino N, Hasegawa E, Akashi K, Abe M, Mieda $\mathrm{M}$, Sakimura K, Sakurai T. GABAergic neurons in the preoptic area send direct inhibitory projections to orexin neurons. Front Neural Circuits 2013;7:192.

131. Chou TC, Bjorkum AA, Gaus SE, Lu J, Scammell TE, Saper CB. Afferents to the ventrolateral preoptic nucleus. J Neurosci 2002;22:977-90.

132. Lu J, Sherman D, Devor M, Saper CB. A putative flip-flop switch for control of REM sleep. Nature 2006;441:589-94.

133. Krenzer M, Anaclet C, Vetrivelan R, Wang N, Vong L, Lowell BB, Fuller PM, Lu J. Brainstem and spinal cord circuitry regulating REM sleep and muscle atonia. PLoS One 2011;6:e24998.

134. Boucetta S, Cissé Y, Mainville L, Morales M, Jones BE. Discharge profiles across the sleep-waking cycle of identified cholinergic, GABAergic, and glutamatergic neurons in the pontomesencephalic tegmentum of the rat. J Neurosci 2014;34:470827.

135. Van Dort CJ, Zachs DP, Kenny JD, Zheng S, Goldblum RR, Gelwan NA, Ramos DM, Nolan MA, Wang K, Weng FJ, Lin Y, Wilson MA, Brown EN. Optogenetic activation of cholinergic neurons in the PPT or LDT induces REM sleep. Proc Natl Acad Sci U S A 2015;112:584-9.

136. Tarun A, Wainstein-Andriano D, Sterpenich V, Bayer L, Perogamvros L, Solms M, Axmacher N, Schwartz S, Van De Ville D. NREM sleep stages specifically alter dynamical integration of large-scale brain networks. iScience 2020;24:101923.

137. Huang Z, Zhang J, Wu J, Mashour GA, Hudetz AG. Temporal circuit of macroscale dynamic brain activity supports human consciousness. Sci Adv 2020;6:eaaz0087.

138. Dehaene S, Changeux JP. Experimental and theoretical approaches to conscious processing. Neuron 2011;70:200-27.

139. Berkovitch L, Dehaene S, Gaillard R. Disruption of conscious access in schizophrenia. Trends Cogn Sci 2017;21:878-92.

140. Karnani MM, Jackson J, Ayzenshtat I, Hamzehei Sichani A, 
Manoocheri K, Kim S, Yuste R. Opening holes in the blanket of inhibition: localized lateral disinhibition by VIP interneurons. J Neurosci 2016;36:3471-80.

141. Muñoz W, Tremblay R, Levenstein D, Rudy B. Layer-specific modulation of neocortical dendritic inhibition during active wakefulness. Science 2017;355:954-59.

142. Jensen O, Mazaheri A. Shaping functional architecture by oscillatory alpha activity: gating by inhibition. Front Hum Neurosci 2010;4:186.

143. Avena-Koenigsberger A, Misic B, Sporns O. Communication dynamics in complex brain networks. Nat Rev Neurosci
2017;19:17-33.

144. Lehembre R, Marie-Aurélie B, Vanhaudenhuyse A, Chatelle C, Cologan V, Leclercq Y, Soddu A, Macq B, Laureys S, Noirhomme Q. Resting-state EEG study of comatose patients: a connectivity and frequency analysis to find differences between vegetative and minimally conscious states. Funct Neurol 2012;27:41-7.

145. Stefan S, Schorr B, Lopez-Rolon A, Kolassa IT, Shock JP, Rosenfelder M, Heck S, Bender A. Consciousness indexing and outcome prediction with resting-state EEG in severe disorders of consciousness. Brain Topogr 2018;31:848-62. 